marked that the right (the wounded) side remained weaker, and longer liable to twitchings, than the left side. The cure progressed almost uninterruptedly, though the patient fell off rapidly in flesh; and on the 12 th of May his pulse became so pereeptibly weaker, that he was allowed a glass of sherry and a basin of soup, daily, under which he, in a few days, began to gather strength.

He was very soon got under the influence of the mercury: on the 11th of May, his month being affected, the calomel and ointment were discontinued. At the commencement of the treatment, five drachms of either were required to produce a full effect; but as the symptoms declined, a less quantity, or four drachms, was found sufficient; and the last dose, only three drachms (June 15th instant), produced such a powerful effect, causing so great a degree of stupor and prostration as to create some alarm. The inhalation was supposed carried far enough, when the respiration became short and hurried, the eyes staring, and the arms dropped by the side. From the 4 th to the 22 nd of May the inhelation was repeated twice a day; from the 22nd to the 28th, once daily; and from the

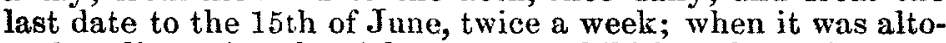
gether discontinued. After every exhibition, the patient expressed immediate relief. On the 14th of the month he was able to rise without assistance; on the $18 \mathrm{th}$ he could walk a short way, with the help of a stick; and on the $23 \mathrm{rd}$ he was able to move out of doors. After this date he gained strength rapidly, and now (the 18th of $\mathrm{June}$ ) is quite recovered. The ether was persevered in so long, on account of the slight pain and stiffness experienced in the loins, and the twitches felt during progression in the tendo-Achillis of right side.

The patient became exceedingly fond of the medicine; the taste for it seemed to grow upon him; he watched for the hours of its administration with impatience; he inhaled the vapour with great rigour-especially towards the last; and sometines it required considerable force to withdraw the pipe. It was truly ridiculous to witness the craving he at times evinced for it: he would open and shut the mouth, with a forward motion, as if attempting to follow and seize the pipe and frequently solicited a repetition of the dose in the most pressing manner.

It was very curions to observe the different effects of the ether on this man at different periods of his cure. At first the whole power of the medicine seemed expended in re. ducing the muscular tension, insensibility to pain and some degree of stupor being the only additional symptoms; but as the disease gave way, the effects produced on the mind increased, whilst those on the body became less marked. The artificial disease produced, if it may be so termed, was marked by three distinct stages-first, extreme nervous and muscular prostration; second, reaction, with more or less mental excitement and delusion; and third, a slighter degree of prostration, or a feeling of fatigue and desire for repose.

In the first stage there was flushing of the face and a peculiar expression of countenance, between that of moroseness and vacancy, followed, in a few moments, by a death-like paralysis of the whole frame, which comprised this stage, and continued for a minute or two.

As the second advanced, the patient sat himself up erect, looking wildly about, and then, either remained quiet, keeping his eyes steadfastly fixed on some point or other, or, as was the case more frequently, commenced moving his body about in a variety of ways. Sometimes he would swing his head and body round and round with great rapidity, and the explanation given for such a feat was, that he supposed himself suspended in the air:-at others he would stoop down and execute movements with his hands, (not unlike those of a dog scraping at a rat-hole,) calling out the while, "Allah zullah ada zakan,"which, in English, means, God is pressing him down;--and he often also, during this stage, expressed great alarm, and, among other strange fancies, supposed "the world was at an end," and that " he saw his father, mother, and other friends," who had long since been dead. $\mathrm{He}$ was suspicions of strangers, and very impatient of their presence, sometimes abusing them in no measured terms, ${ }^{*}$ and on such occasions

* Some amusing scenes occurred. A head man of the Hoie, (secret society,) to which Attong belonged, attended, on one occasion, to see the ether administered : he laid hold of the patient's arm, who immediately turned upon and struck out at him most violently. 'The old man, amazed at this audacity on the part of an insignificant member of his Hoie, became greatly enraged, and, shaking his fore-finger in Attong's face, began to remonstrate, with the effect of only exasperating Attong the more, who now attempted to get on his legs, which effort set the old man fairly to his heels. On another occasion, a Siamese doctor came in, and was desired to stand by while the inhalation was proceeding: the patient furiously assaulted him which the doctor was as little disposed to put up with, as he seemed pre pared to expect it: his hair, bristly enough at any time, now actually looked displayed no contemptible knowledge of the various languages spoken in the East,-Siamese, Chinese, Malay, Kling, Hindostanee, \&c.;-but his friends he never forgot, and would cry and caress them, upon any attempt being made to deceive him in respect of them. It was very remarkable, that if roused, and if his attention was forcibly recalled to some previous subject, especially one in which he had much personal interest, he would converse to the point, and very rationally too. The singular features presented by this case, I confess myself quite unable to exyound; the case, however, exhibited many other peculiarities, but I have related enough, and perhaps more than will be credited.

The languor and prostration which succeed and form the third stage, usually induce the patient to seek relief in an hour's repose.

In conclusion I would remark, that Attong is a very quiet industrious man, and a very intelligent one of his class. He does not smoke, and never was an opium smoker.

\section{ON A CASE OF TUBERCULAR PERITONITIS, FOLLOWED BY PERFORATION OF THE ABDOMINAL PARIETES.}

\section{BY EDWARD G. CROOKE, M.D. Edin.}

On January 19, 1849, I was requested to visit Spencer $\mathrm{H}-$ because he continually rejected his food. I found the patient to be a boy, eleven years of age, of a confirmed scrofulons diathesis; body emaciated; head large, very broad at the vertex, forehead protuberant; solerotic bluish-white, irides grey, pupils dilated; skin thin, fair, harsh, and dry to the touch; chest narrow; belly prominent and full; tongue covered with a whitish fur, except at the margin, its papillæe elongated and prominent; breath very foul; pulse small, quick, and wiry; appetite extremely variable; bowels mostly constipated; stools chalky, wanting bile, of very offensive smell; urine scanty, and very high-coloured, depositing directly a copious whitish sediment, which dissolved upon the addition of $\mathrm{N}_{6} \mathrm{H}$, with heat.

The history of the case is as follows:- His mother states, that about eighteen months ago, he was troubled with vomiting immediately upon taking food; the romiting was accompanied by a severe pain in his head. These symptoms were of several weeks' duration, and so severe in character as to confine the boy to the house: during this period he lived prin. cipally upon brandy, with a small quantity of wheaten bread; he was under no particular treatment, having merely an occasional aperient powder exhibited. About last July he began to improve, and up to the beginning of this year his health has continued good. He has been all along very fastidious as to his diet, and always craved for stimulants. His intellectual powers are of a superior order.

Physical Signs.- The chest sounds tolerably clear; the respiratory murmur is rather feeble; a slight dulness exists under the left clavicle, where the respiration is of a bronchial character, and the voice bronchophonous. The hepatic region is fuller than natural; the umbilical is tender to the touch, and at irregular periods, more especially during the night, the seat of a burning twisting pain. The boy states, that he always feels his belly to be too full, to relieve which he lays with his legs drawn up, the head raised, and that he is troubled with an occasional cough, and expectoration of frothy white sputa.

Fully confirmed in my opinion, that all the viscera were the sites of tubercular deposits to a greater or less degree, but that the abdomen was the chief, I prescribed the following medicine:-Mercury with chalk, five grains; powdered rhubarb, seven grains. Make into powders, to be taken at bedtime. Iodide of potassium, sixteen grains; tincture of orange, and tincture of ginger, of each two drachms; compound infusion of gentian, three ounces and a half. Mix. A tablespoonful three times a day. A clyster of warm water is to be given every night. His diet of a light, nutritious kind, and a glass of sherry daily.

The first powder and injection had the effect of checking the vomiting, and produced a copious bilious evacuation. The powder was continued every alternate night for ten days,

pointed as the quills of a porcupine, and he prepaxed to act, and but for $m y$ interference, would have acted, on the offensive. - The case excited much interest among all classes of the native community. Tetanus is by no means uncommon at this place, and is almost always fatal. They were very curious in their examination of the ether; it required to be carefully looked after : on two occasions, a phial containing some was stolen, as, also, were a bladder and pipe used for administering it. 
during which time the boy's appetite became more natural, the tongue cleaner, breath less foul, belly less tumid-in fine, the organic functions more healthy.

Feb. 8th.-The iodide of potassium mixture was replaced by a sulphate of quinine one.

15th.-Was summoned in the evening to see him. He was suffering from a severe diarrhoea; the pain near the umbilicus is much increased, the umbilicus itself retracted. The diarrhœa was checked by mereury with chalk, and compound chalk powder with onium. Six leeches were applied to the umbilicus with considerable benefit.

During the next six weeks, the umbilicus became gradually very prominent and inflamed, as if the seat of abscess. The pain became intense. I was not permitted to open the abscess. The iodide of potassium mixture was again ordered, combined with tincture of opinm; fomentations were continually applied to the abdomen, and the leeching was repeated at intervals.

April 8th.-This morning, the umbilical tumour burst in two places; a vast quantity of puro-fæculent matter escaped, and continued to do so daily; the discharge was increased in quantity about an hour after taking food, and then consisted of half-digested food; from the slight fæcal character, the opening was supposed to be connected with the lower part of the small intestine. Another tumour of the same character appeared about a month after, (early in May,) two inches and a half below the umbilicus; this burst in three places; from the two upper of these a more frecal discharge passed-from the lower, a serous fluid, with small shreds of lymph. During this period, the bowels were opened daily, without aperient medicine, although, as I afterwards learnt, his mother was in the habit of giving him several opium pills daily. The appetite still continued. From caprice, it is now impossible to regulate the diet. In the day, the lad took several ounces of brandy, and, if restricted, would cry and fret to such a degree, that his mother thought it best to let him have his own way. He stated that the brandy relieved the intense pain.

June 28th.-For the last six weeks no visible change has taken place, except that the bowels became obstinately constipated; the pulse is tolerably firm. An occasional pow. der of meretry and chalk, and a warm-water clyster, were exhibited. The constipation is doubtless the effect of the opiates and brandy.

July 3rd.-I was summoned to him, as he appeared dying; the belly is now very much shrunken; the pulse small, soft, and of irregular rhythm; the appetite has declined; the surface of the body cold; the pain at the umbilical orifice is extreme. Upon examination, I found a substance obstructing the discharge, which, when removed, was found to be a piece of half digested onion; upon the administration of a strong stimulant, and the application of external heat, the boy rallied.

Sept. 14th.-The boy is evidently sinking, but slowly; the body is more emaciated; the pulse hardly perceptible; the nervous system more irritable; so much so, that the slightest noise offends; the appetite is entirely gone.

Oct. 1st.-The boy died this morning, three A.M. Fifteen hours after death, $\mathbf{I}$ proceeded to make a post-mortem examination.

Autopsy.-Upon opening the abdominal parietes, the peritonæal surface was found adherent to the omentum, which in its turn adhered to the peritonzeal surface of the intestines; in fact, the omentum could not be distinguished; every particle of its adipose tissue had disappeared; the parietes themselves were excessively attenuated; a large ripe tubercle, about the size of a hazel-nut, was seen in the left iliac region, upon the lower portion of the descending colon; also another, of rather smaller size, upon the anterior peritonæal surface of the stomach; the whole of the intestinal canal was matted together by bands of lymph; at the lower part of the ileum, about six inches from the cæecum, the débris of a large tubercle existed; the bowel was here adherent to the umbilicus, and communicated with the opening there, the orifices below which were but different channels to a large opening in the ileum, about two inches and a half further fron the cæcum; this portion of the intestine was agglutinated to the descending colon, and communicated therewith at the commencement of the sigmoid flexure; the whole peritonæal surfaces were studded with small millet-seed tubercles. The spleen was indurated and enlarged, its surface was also tuberculated; the liver enlarged and congested, but otherwise normal; the kidneys healthy; the whole of the mesenteric glands were of a chalky consistence; the small intestine was empty; Peyer's glands were very indistinetly marked; the large intestine con- tained but a small amount of frecal matter, of a yellow ocrish colour, and firm consistence; its valvulæ-conniventes were with difficulty distinguished. About three ounces of serum were found in the cavity. I regret that circumstances prevented my opening the head and thorax.

Leyland, Lancashire, 1849.

\section{Iforégn 理epartment.}

\section{Ptyalism resulting from Cauterization with the Acid Nitrate of Mercury.}

Dr. Laforgue, of Toulouse, states, in $L$ 'Union Médicale, that a lady under his care, fifty-four years of agc, of a fceble constitution, and very nervous, had been for some time subject to severe attacks of menorrhagia. This had resisted all ordinary astringents, when it was discovered that the cervix uteri was ulcerated, and in an indurated state much resembling scirrhus. Cauterizations with the nitrate of silver were first used, but these proving ineffectual, the neck of the uterus was tonched with the acid nitrate of mercury two different times. Cold water was injected into the uterus before the speculum was withdrawn, and a sponge, wet with the same fluid, left on the cervix. A few hours afterwards, nausea, vomiting, tenesmus, and shivering came on; these symptoms were subdued by appropriate means, but on the third day, the internal surface of the cheek became painfnl and swollen, and the gums sore, though no salivation was taking place. She gradually recovered these symptoms, and the next cauterization will be by the hot iron.

\section{The late Cholera in Paris.}

The Prefect of Police has sent to the Academy of Medicine documents detailing the mortality in private life, from the beginning of the epidemic to the month of October. The deaths are distributed over the various months in the following manner:-March, 130; April, 694; May 2426; June, 5769; July, 419; August, 810; September, 670; October, 32: total, 10,950 . If to this number, 6911 deaths, which occurred in hospitals and asylums, be added, we shall have 17,861 deaths, which, with upwards of 2000 fatal cases in the military hospitals, will swell the number to 20,000 . This amount is almost one-third more than the number of individuals who died during the former epidemic. A list is likewise given of the mortality per district, and we find, as might have been expected, that the deaths were most numerous where indigence, uncleanliness, and intemperance are combined. The twelfth district had 1759 deaths, and the fifth, sixth, eighth, and tenth almost as much, these being very closely populated, and in very distressing hygien:c circumstances. The other districts, more thinly populated and more cleanly, are much below the foregoing in the losses they have sustained during the prevalence of the disease.

Report of the Committee of the Chinese Hospital, Shanghae, for the period of eighteen months, from July 1st, 1847, to December 31st, 1848.

Instead of the report of the hospital ending in June, as on former occasions, it has been determined by the committee to present it for eighteen months, and thus bring it down to the end of the year; so that, in future, the report of proceedings will be from January to December, and will close just before the period for holding the annual meeting. Then the report, as passed by the annual meeting here, can be sent down to the Medical Missionary Society at Hong Kong, and added to the general report of the society.

During the past summer, the weather has been unusually wet and cold, with much easterly wind. During the whole of the latter months, the thermometer never rose above $92^{\circ}$; and in July there was a severe typhoon, accompanied by a flood, which deluged the surrounding country. During the storm, the barometer fell an inch, or an inch and a half, the wind being chiefly from the east and north-east. As the tide. rose, the water was forced up the river, and by the time it was three-quarters flood, the neighbourhood of the river was all under water, to the depth of three feet. The time of high water was five P.M., but, happily, at two P.M. the wind ceased, and there was a dead calm for half-an-hour, when it began to blow from the south, and afterwards violently from the southwest and west. Had the wind continued to blow from the north-east during the whole time of flood tide, much more injury would have been done to the European settlement, as well as to the Chinese town. During the storm, much 